\title{
Exercise-Induced Biological and Psychological Changes in Overweight and Obese Individuals: A Review of Recent Evidence
}

\author{
Petros C. Dinas, ${ }^{1,2}$ Aleksandra S. Markati, ${ }^{3}$ and Andres E. Carrillo ${ }^{4}$ \\ ${ }^{1}$ School of Sport, Performing Arts and Leisure, University of Wolverhampton, Walsall WS1 3BD, UK \\ ${ }^{2}$ FAME Laboratory, Institute of Research and Technology Thessaly, Centre for Research and Technology Hellas, 42100 Trikala, Greece \\ ${ }^{3}$ Department of Physical Education and Sport Science, Kapodistrian University of Athens, 17237 Athens, Greece \\ ${ }^{4}$ Department of Exercise Science, Chatham University, Pittsburgh, PA 15232, USA
}

Correspondence should be addressed to Petros C. Dinas; p.ntinas@wlv.ac.uk

Received 10 November 2013; Accepted 23 December 2013; Published 6 February 2014

Academic Editors: A. Bielli, A. N. Kavazis, and A. Tse

Copyright (C) 2014 Petros C. Dinas et al. This is an open access article distributed under the Creative Commons Attribution License, which permits unrestricted use, distribution, and reproduction in any medium, provided the original work is properly cited.

On a global scale, the most recent evidence indicates that over 400 million adults are obese while $\sim 20$ million children and 1.6 billion adults are overweight. The World Health Organization reveals that, by the year 2015, 2.3 billion adults will be overweight and more than 700 million will be obese. In this review paper we summarized the current evidence to elucidate the impact of exercise training on biological and psychological health indices in overweight and obese individuals. Endocrine function indices that are discussed herein include leptin, adiponectin, growth hormone, and ghrelin levels. Psychological factors include anxiety and depression, body image, and motivation for exercise. Overall, exercise promotes physical and psychological health in overweight and obese individuals particularly because exercise-induced adaptations occur across a multitude of systems within the active human. The impact of exercise on specific biological and psychological health indices contributes to overall health in overweight and obese individuals.

\section{Introduction}

Increased adiposity and physical inactivity have been identified as harmful health indices [1]. It has been widely acknowledged that obesity leads to health problems such as cardiovascular disease, type 2 diabetes, and hypertension $[2,3]$. On a global scale, the most recent evidence indicated that over 400 million adults are obese while $\sim 20$ million children and 1.6 billion adults are overweight [2]. An unpleasant estimation by the World Health Organization revealed that by the year 2015 $\sim 2.3$ billion adults will be overweight and more than 700 million will be obese [2]. Thus, it is necessary to establish practical/cost effective strategies as well as update and renew current health initiatives, such as physical activity participation, that will lessen the risk of weight gain and disease in overweight and obese populations.

It is well known that physical activity contributes, at least in part, to a healthy quality of life [4]. Indeed, compelling evidence supports that cardiorespiratory fitness (an objective measure of habitual physical activity) is an independent predictor of all-cause and cardiovascular disease mortality [5]. Specifically, recent evidence indicates that individuals with the highest level of physical activity had a greater total life expectancy compared to individuals with low physical activity participation $[6,7]$. Conversely, physical inactivity has been linked to a plethora of health conditions such as type 2 diabetes [2] and has been identified as a greater risk for morbidity and mortality than a large adipose tissue mass [8]. In this light, it is essential to constantly monitor relevant research, which continues to provide nascent exerciseinduced adaptations that are invaluable for weight management, disease prevention, and to establish a high quality of life.

The aim of this paper was to review and summarize the current biological and psychological evidence to further understand the relationship between exercise and health in overweight and obese individuals. 


\section{Approach}

A search in PubMed and Science Direct was conducted using key words relevant to exercise and obesity (e.g., overweight, obesity, and weight loss) as well as appropriate biological and psychological terms (e.g., adipose tissue, lipids, anxiety, and hormones). The search also included the articles cited in the identified papers. All papers included in this review were identified by all three authors for their relevance according to the aim of the paper.

\section{Exercise Training and Weight Management}

3.1. Definitions. Physical inactivity is defined as very low or no bodily movement that requires energy expenditure. On the other hand, physical activity is defined as the total of the daily movements produced by skeletal muscles causing energy expenditure including programmed exercise [9].

Percent body fat is an index used to determine an individual's health status and is calculated by dividing the total weight of fat by total weight. An essential amount of body fat is necessary to maintain life (i.e., $3-5 \%$ in men and $10-16 \%$ in women), but excessive amounts can lead to health problems such as chronic inflammation [10, 11].

Body mass index (BMI) was established to estimate a human's body category based on weight in relation to height. BMI is calculated as weight $(\mathrm{kg})$ divided by height $(\mathrm{m})$ squared. Obesity classifications based on BMI for overweight, class I obese, and class II obese are $25-29.9 \mathrm{~kg} / \mathrm{m}^{2}, 30-$ $34.9 \mathrm{~kg} / \mathrm{m}^{2}$, and $>35 \mathrm{~kg} / \mathrm{m}^{2}$, respectively [2].

Waist-to-hip ratio is calculated as the ratio of the smallest diameter of the waist (waist circumference) and the circumference of the largest diameter of the hips (hip circumference). Waist circumference is a surrogate for abdominal obesity and is an independent risk factor for cardiovascular disease [12]. Waist-to-hip ratios $>1$ in men and $>0.85$ in women indicate a greater risk for disease [13]. However, BMI and waist-to-hip ratio cannot describe the body composition and therefore they should be used by taking into consideration this limitation.

Maximal oxygen uptake $\left(\mathrm{VO}_{2} \max \right)$ is a valid measurement to determine physical fitness [14]. $\mathrm{VO}_{2}$ max is measured in milliliters of oxygen per kilogram of bodyweight per minute $(\mathrm{mL} / \mathrm{kg} / \mathrm{min})$ and represents the maximum capacity of an individual's body to consume, transport, and utilize oxygen during incremental exercise (aerobic threshold).

\subsection{Exercise and Body Weight Regulation in Overweight and} Obese Individuals. Overweight and obese individuals are repeatedly suggested to follow two important health recommendations that can reduce the risk of health problems; that is, eat less and be more physically active. These lifestyle recommendations are important because only $\sim 25-30 \%$ of lifespan variation can be attributed to genetic factors [15]. Thus, it is critical to continuously update and renew health strategies that can contribute to lifestyle modification of overweight and obese individuals. It remains difficult to prescribe an exact amount of exercise relevant to obese and overweight populations that can prevent weight gain, particularly because each person requires an individualistic approach to maximize the benefits gained from exercise training. Nevertheless, evidence suggests that any amount of exercise can be effective in weight management of overweight and obese individuals. For example, a ten-month after school physical activity intervention in young boys ( $~ 50 \%$ of participants were overweight or obese) resulted in a significant reduction in BMI, fat mass, and percent body fat compared to the control group [16]. Each after school activity consisted of a 25 min skills instruction session, a $35 \mathrm{~min}$ aerobic exercise session, and a $20 \mathrm{~min}$ stretching session [16]. At the other end of the age spectrum, six months of Danhak exercise training in elderly Korean individuals that included brain respiration exercises (i.e., gymnastics, laughter, and massages) resulted in a significant reduction of percent body fat and waist-to-hip ratio as well as a nonsignificant reduction in body weight and BMI [17].

Exercise has also been shown to reduce adipose tissue mass that resulted in significant weight loss [18]. Specifically, a 16-week exercise training study showed that a combined aerobic (treadmill, elliptical machines, and aerobic classes) and resistance exercise (upper and lower body strength exercises) training program resulted in a greater reduction of multiple adiposity outcomes (i.e., body weight, BMI, total body fat, and fasting glucose) in 41 overweight Latina adolescent girls compared to a resistance exercise training group [18]. Indeed, exercise induces various health benefits such as a reduction in fat mass, as well as a decreased risk of cardiovascular disease, diabetes, musculoskeletal disorders, and some cancers (i.e., endometrial, breast, and colon) [2]. Evidence suggests, however, that the aforementioned exercise-induced adaptations can also occur independent of weight loss. For example, 13 weeks (five times per week) of supervised aerobic exercise (60 min at $60 \%$ peak oxygen uptake) significantly reduced total and abdominal fat in obese individuals with type 2 diabetes [19] as well as minimized the presence of cardiovascular disease risk factors without an overall loss in body weight [20]. In addition, a 12-week exercise intervention (walking or light jogging on a treadmill, 5 times/week, $60 \% \mathrm{VO}_{2}$ max, $60 \mathrm{~min} / \mathrm{session}$ ) led to reductions in fasting interleukin-6 (IL6 ) and in waist circumference in obese men with or without type 2 diabetes, without a reduction in overall body weight [21].

Although exercise alone plays a critical role in weight maintenance, [22] when exercise is combined with appropriate dietary interventions, a larger weight loss is reported [23]. Indeed, it has been suggested that the most effective weight-loss programs should include a combination of diet, exercise, and behavioral modifications [24-26]. A recent study reported that women with higher physical activity participation and dietary restraint had a significantly lower BMI compared to women with higher physical activity participation and lower dietary restraint [27]. In the same study it was also found that women with lower physical activity participation and reduced hunger levels had significantly lower BMI compared to women with lower physical activity participation and higher levels of hunger [27]. These data suggest that 
TABLE 1: Summary of the studies examined herein showing the effects of exercise on weight management, leptin, adiponectin, growth hormone, and ghrelin levels in overweight and obese individuals.

\begin{tabular}{|c|c|c|c|c|}
\hline Study & Exercise type & Individuals & Exercise characteristics & Results \\
\hline Halle et al., 1999 [28] & Aerobic & $\begin{array}{l}\text { Obese/type } 2 \\
\text { diabetic }\end{array}$ & $\begin{array}{l}4 \mathrm{wk}, 5 \text { days/wk, } 30 \mathrm{~min} / \text { day, } 70 \% \text { of } \\
\mathrm{VO}_{2} \max \end{array}$ & $\begin{array}{l}\downarrow \text { leptin levels, } \downarrow \text { body } \\
\text { weight }\end{array}$ \\
\hline Yamaguchi et al., 2011 [29] & $\begin{array}{l}\text { High } \\
\text { intensity } \\
\text { aerobic }\end{array}$ & $\begin{array}{l}\text { Obese/type } 2 \\
\text { diabetic }\end{array}$ & $\begin{array}{l}4 \mathrm{wk}, 2 \text { times/day, } 30 \mathrm{~min} / \text { day, } \\
\text { anaerobic threshold }\end{array}$ & $\begin{array}{l}\text { Significantly negative } \\
\text { correlation of growth } \\
\text { hormone levels with } \\
\text { visceral fat }\end{array}$ \\
\hline Hunter et al., 2010 [30] & $\begin{array}{l}\text { Aerobic and } \\
\text { resistance }\end{array}$ & $\begin{array}{l}\text { Overweight } \\
\text { women }\end{array}$ & $\begin{array}{l}8 \mathrm{wk} ; \text { aerobic: } 2 \text { days/wk, } 40 \mathrm{~min} \text {, } \\
80 \% \mathrm{VO}_{2} \text { max; resistance: } 2 \\
\text { days/wk, } 11 \text { exercises, } 2 \text { sets } / 10 \\
\text { repetitions }\end{array}$ & $\begin{array}{l}\text { Regain } 3.5 \mathrm{~kg} / \mathrm{body} \text { weight } \\
\text { compared to } 6.4 \mathrm{~kg} \text { of the } \\
\text { nonexercisers }\end{array}$ \\
\hline Davis et al., 2009 [18] & $\begin{array}{l}\text { Aerobic and } \\
\text { resistance }\end{array}$ & $\begin{array}{l}\text { Overweight } \\
\text { adolescent girls }\end{array}$ & $\begin{array}{l}16 \mathrm{wk}, 5 \text { days } / \mathrm{wk}, 30 \mathrm{~min} \text { aerobic }+ \\
30 \mathrm{~min} \text { resistance }\end{array}$ & $\begin{array}{l}\downarrow \text { body weight, BMI, total } \\
\text { body fat and fasting glucose }\end{array}$ \\
\hline Irving et al., 2009 [31] & Aerobic & $\begin{array}{l}\text { Obese/metabolic } \\
\text { syndrome }\end{array}$ & $\begin{array}{l}16 \mathrm{wk}, 3-5 \text { days } / \mathrm{wk} \\
350-400 \mathrm{kcal} / \mathrm{session}\end{array}$ & $\uparrow$ growth hormone levels \\
\hline Ross et al., 2000 [32] & Aerobic & Obese men & $\begin{array}{l}\text { 3-month, energy expenditure per } \\
\text { exercise session } 700 \mathrm{kcal}\end{array}$ & $8 \% \downarrow$ body weight \\
\hline Leidy et al., 2004 [33] & Aerobic & Overweight & $\begin{array}{l}3 \text {-month, } 5 \text { times } / \text { wk, } 70-80 \% \mathrm{VO}_{2} \\
\max , 480 \pm 126 \mathrm{kcal} / \text { session }\end{array}$ & $\uparrow$ ghrelin levels \\
\hline Redman et al., 2010 [34] & Aerobic & Overweight & 6-month, 5 days/wk, $30-60 \mathrm{~min}$ & $\uparrow$ ghrelin levels \\
\hline Kondo et al., 2006 [35] & Aerobic & Obese & $\begin{array}{l}\text { 7-month, } 4-5 \text { days/wk, } \\
30-60 \mathrm{~min} / \text { day, } 60-70 \% \mathrm{VO}_{2} \max \end{array}$ & $\uparrow$ adiponectin levels \\
\hline
\end{tabular}

$\mathrm{VO}_{2}$ max: maximal oxygen uptake, kg: kilograms, BMI: body mass index, kcal: kilocalories.

eating behavior modifications along with physical activity participation are important when designing weight management strategies.

A major concern for overweight and obese individuals is weight regain following a dietary intervention specific for weight loss. Exercise training, however, appears to limit the amount of weight regain after such interventions. For example, Hunter and colleagues [30] examined weight regain in healthy premenopausal overweight women after one year of following a dietary intervention in which the participants lost $12.3 \pm 2.5 \mathrm{~kg}$. The women were divided into five groups including aerobic exercise adherers, aerobic exercise nonadherers, resistance exercise adherers, resistance exercise nonadherers, and a sedentary control group. Active participants (i.e., aerobic and resistance exercise) exercised two times per week. The aerobic exercise program included running on the treadmill for 20 min at $67 \% \mathrm{VO}_{2}$ max during the first week and gradually increased to $40 \mathrm{~min}$ of running at $80 \% \mathrm{VO}_{2}$ max by the eighth week. The resistance exercise program included two sets of 10 repetitions (at $80 \%$ of 1 repetition maximum) of squats, leg extension, leg curl, elbow flexion, triceps extension, lateral pull-down, bench press, military press, lower back extension, and bent leg sit-ups. The results revealed that both aerobic and resistance exercisers regained $3.5 \mathrm{~kg}$ after one year compared to $6.4 \mathrm{~kg}$ of weight regained by the nonexercisers [30]. Thus, exercise has a critical role in the maintenance of body weight that should be included in lifestyle modification programs. The effects of exercise on weight management in overweight and obese individuals are summarized in Table 1.

\section{Biological Adaptations}

Common health risk factors associated with overweight and obesity include insulin resistance, high cholesterol, and visceral fat accumulation [2]. These health factors are widely important given their connection with the pathogenesis and exacerbation of diseases such as type 2 diabetes and atherosclerosis [2]. Weight loss and maintenance, however, have been shown to improve several health indices such as systolic and diastolic blood pressure, glycemic control, inflammation, and an individual's lipid profile. Regulation of the aforementioned health indices through body weight maintenance is widely important because of an associated increase in life expectancy [36]. In this light, we have examined the effects of exercise on a few critical biological risk factors associated with overweight and obesity.

4.1. Endocrine Function. Certain human organs, such as adipose tissue, secrete peptides and adipokines that stimulate biological processes throughout the body. An increased adipose tissue mass elevates the production of certain adipokines that may lead to the disruption of biological processes such as immune function, insulin sensitivity, and blood pressure $[37,38]$. Exercise, however, plays a vital role in the regulation of hormonal activity within adipose tissue and other major endocrine organs [39].

4.1.1. Leptin. Leptin is an adipokine that is produced and secreted by adipocytes and is characterized as a satiety peptide because of its role in food intake regulation [40,41]. 
In order to regulate hunger, circulating leptin is detected by receptors in the hypothalamus where it inhibits appetite [41]. Despite having greater levels of circulating leptin, obese individuals may experience a condition referred to as leptin resistance that leads to inadequate communication with the hypothalamus [41]. Evidence suggests that leptin sensitivity stimulates lipolysis in adipose tissue and hepatic fatty acid uptake and oxidation [42]. Recent data, however, showed that increased inflammatory cytokines and free fatty acid levels were associated with impaired leptin sensitivity in mice $[41,43]$. Indeed, circulating leptin levels in humans have been associated with greater levels of systemic inflammation and fat mass [41]. Thus, increased circulating leptin, which may indicate leptin resistance, may be involved with the development of adipose tissue accumulation [41].

The extent to which exercise may influence leptin concentrations depends on (i) the leptin circadian rhythm, (ii) energy spent during an exercise session, (iii) resting leptin levels, (iv) sex, and (v) postprandial time prior to exercise [41]. Evidence from normal weight humans suggests that short-term exercise (i.e., five days, $30 \mathrm{~min} /$ day, at $25 \%$ and at $75 \% \mathrm{VO}_{2} \max$ ) does not lead to a change in leptin levels [44]. Specifically, acute exercise (i.e., treadmill exercise at $90 \% \mathrm{VO}_{2}$ $\max$ for $5 \mathrm{~min}$ or $100 \% \mathrm{VO}_{2}$ max for $2 \mathrm{~min}$ ) did not modify circulating leptin concentrations in well-trained adult men (28.71 \pm 2.91 years) [45]. Chronic exercise, however, may reduce leptin particularly when exercise training is accompanied by a reduction in fat mass [28, 41, 46, 47]. Four weeks of cycling (30 min/day, 5 days/week) at $70 \% \mathrm{VO}_{2}$ max led to a reduction of circulating leptin in obese adult males $(48.0 \pm$ 8.0 years) with type 2 diabetes that was accompanied by a loss of body weight [28]. Further, the change in leptin concentrations was associated with fat loss in postmenopausal women after nine months of walking, jogging, and stair climbing [46]. The supervised exercise program implemented in the aforementioned study was performed three days/week and gradually increased in frequency and intensity to 45-50 min at $60-70 \% \mathrm{VO}_{2} \max [46]$. Conversely, 20 weeks of cycling (50 min, 3 days/week) at 55\% $\mathrm{VO}_{2}$ max did not lead to a change of circulating leptin in adult males and females [47]. Thus, particularly when accompanied by weight loss, exercise training has been shown to reduce leptin levels and enhance leptin sensitivity [43].

4.1.2. Adiponectin. Adiponectin is an adipokine that affects energy homeostasis and insulin sensitivity. High levels of adiponectin appear to reduce circulating levels of free fatty acids [48] as well as lessen glucose production from the liver that is likely due to enhanced insulin sensitivity $[48,49]$. On the other hand, low levels of adiponectin have been associated with increased appetite and impaired insulin sensitivity [41]. Indeed, a study in mice revealed that decreased levels of adiponectin in muscle were associated with hyperinsulinemia and dyslipidemia [50].

Recent research revealed that acute aerobic exercise (>60 min at $\sim 60 \% \mathrm{VO}_{2} \max$ ) increased circulating adiponectin levels $[51,52]$. These findings, however, could be due to hemoconcentration or normal postprandial diurnal changes $[51,52]$. On the other hand, a chronic aerobic exercise intervention (7 months of cycling, $60-70 \%$ of $\mathrm{VO}_{2}$ max, 45 days/week) in obese Japanese individuals increased adiponectin levels which was relative to the amount of weight loss [35]. Therefore, acute and chronic exercise has been shown to positively influence circulating adiponectin.

4.1.3. Growth Hormone. Another risk factor for disease related to overweight and obesity is increased abdominal adiposity that is associated with reduced growth hormone [53]. Reduced growth hormone secretion is associated with increased fat mass and with the development of the metabolic syndrome and type 2 diabetes [31]. Growth hormone may increase the basic metabolic rate leading to increase in energy expenditure in obese individuals [31]. A recent study showed that, after 16 weeks of supervised exercise training, growth hormone levels increased and were associated with reduced abdominal fat in obese adults with the metabolic syndrome [31]. Similarly, when exercise was performed at the anaerobic threshold (i.e., $30 \mathrm{~min}, 2$ times/day for 4 weeks), growth hormone levels correlated negatively with visceral fat but did not correlate with subcutaneous fat in obese individuals with type 2 diabetes [29]. Thus, exercise may be an effective strategy for increasing growth hormone secretion that is related to the reduction of abdominal fat in obese adults.

4.1.4. Ghrelin. Ghrelin is produced in the stomach and is an endogenous ligand for the growth hormone secretogogue receptor [41]. There are two forms of ghrelin, that is, (i) the acylated form that binds to the secretogogue receptor and (ii) the nonacylated form that does not bind to the secretogogue receptor [41]. Both forms stimulate human skeletal myoblasts that may indicate the presence of an unknown receptor for the nonacylated form [54]. Increased circulating levels of ghrelin induce an orexigenic effect, that is, a stimulation of the peripheral hunger signal to the central nervous system [41]. Thus, circulating ghrelin levels are reduced after feeding. Furthermore, in a recent in vitro study ghrelin inhibited the expression of inflammatory cytokines interleukin-1 $\beta$, IL-6, and tumor necrosis factor- $\alpha$ (TNF- $\alpha)$ [55] as well as induced the expression of the anti-inflammatory cytokine interleukin$10[56]$.

A recent study reported no change in total ghrelin assessed in obese individuals participating in a short-term (i.e., 3-week) weight loss and exercise training program [57]. Long-term exercise (i.e., 3 days/week for 12 weeks), however, increased total circulating ghrelin concentrations which was also negatively associated with inflammatory biomarkers [58]. Similarly, another study in overweight individuals suggested that caloric restriction and weight loss along with chronic exercise (i.e., 3 months, 5 times/week at $70-80 \%$ of $\mathrm{VO}_{2}$ max, energy expenditure $480 \pm 126 \mathrm{kcal} / \mathrm{session}$ ) led to increased levels of total circulating ghrelin concentrations [33]. Further, six months of exercise five times per week ( $\sim 50$ minutes per session with an energy cost of $\sim 450 \mathrm{kcal}$ ) increased levels of total circulating ghrelin concentrations [34]. Nevertheless, further work in this area is necessary to 
examine the relationship between long-term exercise training, ghrelin, and inflammation in overweight and obese individuals. The effects of exercise on the aforementioned hormones in overweight and obese individuals are summarized in Table 1.

4.2. Inflammation. Overweight and obesity are strongly positively correlated with chronic inflammation [10]. Chronically inflamed individuals may experience macrophage infiltration of adipose tissue that leads to the production of cytokines such as IL-6 that activate the immune system [59]. Additionally, chronically high levels of circulating inflammatory cytokines are associated with impaired insulin sensitivity that may indicate a high risk for type 2 diabetes [59]. As mentioned above, adipose tissue is responsible for the secretion of adipokines such as adiponectin, leptin, and resistin, as well as immune factors such as TNF- $\alpha$, IL-6, and plasminogen activator inhibitor-1 $[10,59]$. These substances play a crucial role in the pathogenesis of the metabolic syndrome $[59,60]$. Furthermore, increased levels of the proinflammatory biomarker TNF- $\alpha$ appear to be associated with reduced circulating adiponectin levels [61]. Indeed, a potential mechanism for the exercise-induced increase in adiponectin is a reduction in circulating levels of TNF- $\alpha$ [62].

Exercise may have potent anti-inflammatory properties in overweight and obese individuals, particularly when the intensity of exercise is high [63]. For example, after a group of obese men performed a single bout of exercise on the treadmill at 55\% $\mathrm{VO}_{2}$ max, IL-6 was significantly reduced in adipose tissue but not in circulation which may indicate a local adipose tissue anti-inflammatory response to acute exercise [20]. Furthermore, a significant reduction in IL-6 and C-reactive protein levels was observed in obese adolescent men following participation in a 12 -week aerobic exercise training program (5 days/week, 40 minutes a day at a moderate intensity) [64]. Moreover, a 6-month aerobic exercise training program (4 times/week, 45-60 min/session) exerted anti-inflammatory effects in overweight individuals with type 2 diabetes [65]. Conversely, Arsenault et al. [66] reported no change in C-reactive protein, IL- 6 , and TNF- $\alpha$ in overweight and obese postmenopausal women following participation in a 6-month exercise training program (3-4 sessions/week, $60 \% \mathrm{VO}_{2} \max , 12 \mathrm{kcal} / \mathrm{kg} /$ week) [66]. In summary, exercise training appears to exert anti-inflammatory effects that may be due to, at least in part, a reduction in body weight, total body fat, and visceral fat that leads to enhanced endocrine activity and reduced inflammatory biomarkers secreted by adipocytes and immune cells [67]. The effects of exercise on inflammatory biomarkers in overweight and obese individuals are summarized in Table 2.

4.3. Insulin Sensitivity. It is well known that insulin resistance is a major concern for overweight and obese individuals [68]. Exercise increases energy expenditure that has been shown to improve insulin sensitivity which is the major concern of an individual suffering from type 2 diabetes [69]. Indeed, several studies revealed that exercise led to enhanced insulin sensitivity in overweight and obese individuals. For example, one study showed that 3 months of aerobic exercise (i.e., brisk walking or light jogging with an energy expenditure of $700 \mathrm{kcal}$ per session) improved insulin sensitivity that was accompanied by an $8 \%$ reduction in body weight [32]. Results from the same experiment also showed that participants without weight loss after the 3-month intervention experienced no change in insulin sensitivity. Insulin sensitivity, however, was measured four days after the last exercise session and, therefore, the short-term effects of an acute exercise session were not included in the assessment [32]. It is likely, however, that exercise training interventions without weight loss could lead to an improvement in insulin sensitivity. For example, Nassis and colleagues [70] reported that a 12-week aerobic exercise training program (3 days/week, $40 \mathrm{~min} /$ session) improved insulin sensitivity in overweight and obese adolescent girls, without any changes in body weight and body fat [70].

Other studies have shown conflicting results regarding the impact of exercise on insulin sensitivity. For example, a 12-week aerobic exercise training program (i.e., slow running 5 times/week for $40 \mathrm{~min} /$ session) improved insulin sensitivity in obese adolescent men who lost a significant amount of weight but remained obese after exercise training [64]. Conversely, no significant changes in insulin sensitivity were observed in middle-aged obese women after participation in a 48 -week resistance exercise training program (40 min/session, 2 sets/exercise, 14 repetitions/set) [71]. Similarly, a study of 115 older overweight and obese adults showed that 6 months of exercise training, prescribed from the guidelines of the American College of Sports Medicine, significantly reduced body fat levels but did not influence insulin sensitivity [72].

It is also suggested that exercise in combination with a dietary intervention is an effective nonpharmaceutical treatment for improving insulin sensitivity in older, overweight, and obese individuals [73]. Indeed evidence showed that insulin sensitivity was significantly improved in individuals following a combined 12-week aerobic exercise (5 days/week, 50-60 min/day at $75 \% \mathrm{VO}_{2} \max$ ) and dietary intervention compared to individuals who performed exercise alone [74]. The effects of exercise training on insulin sensitivity are still under investigation, yet insulin sensitivity may be acutely enhanced after certain exercise interventions. The effects of exercise on insulin sensitivity in overweight and obese individuals are summarized in Table 2.

4.4. Dyslipidemia. Obesity is positively correlated with lipid levels in circulation which indicates a higher risk for cardiovascular disease. Indeed, increased levels of triglycerides, cholesterol, low density lipoproteins, and decreased levels of high density lipoproteins indicate a problematic lipid profile that results in an increased risk of heart disease [2, 75]. Exercise training at a moderate intensity has been shown to improve the lipid profile independent of weight loss [75]. Specifically, exercise has been positively associated with increased high density lipoproteins and negatively associated with triglycerides in overweight and obese adults with 
TABLE 2: Summary of the studies examined herein showing the effects of exercise on insulin sensitivity, lipid profile, and inflammatory markers in overweight and obese individuals.

\begin{tabular}{|c|c|c|c|c|}
\hline Study & Exercise type & Individuals & Exercise characteristics & Results \\
\hline Dekker et al., 2010 [20] & Aerobic & Obese & 1 exercise bout, $55 \% \mathrm{VO}_{2} \max$ & $\downarrow$ IL-6 \\
\hline Dekker et al., 2007 [21] & Aerobic & Obese & $\begin{array}{l}12 \mathrm{wk} \text {, treadmill walking or light } \\
\text { jogging, } 5 \text { times/wk, } 60 \% \mathrm{VO}_{2} \max \text {, } \\
60 \mathrm{~min}\end{array}$ & $\begin{array}{l}\downarrow \text { IL-6, } \downarrow \text { waist } \\
\text { circumference }\end{array}$ \\
\hline Shih et al., 2010 [64] & Aerobic & $\begin{array}{l}\text { Obese adolescent } \\
\text { men }\end{array}$ & $12 \mathrm{wk}, 5$ times/wk, $40 \mathrm{~min} / \mathrm{session}$ & $\downarrow$ IL-6, $\uparrow$ insulin sensitivity \\
\hline Kadoglou et al., 2007 [65] & Aerobic & $\begin{array}{l}\text { Overweight/type } \\
2 \text { diabetic }\end{array}$ & $\begin{array}{l}\text { 6-month, } 4 \text { times/wk, } \\
45-60 \mathrm{~min} / \mathrm{session}\end{array}$ & $\begin{array}{l}\downarrow \text { C-reactive protein and } \\
\text { IL- } 18, \uparrow \text { IL- } 10\end{array}$ \\
\hline Arsenault et al., 2009 [66] & Aerobic & $\begin{array}{l}\text { Overweight and } \\
\text { obese } \\
\text { postmenopausal } \\
\text { women }\end{array}$ & $\begin{array}{l}\text { 6-month, } 3 \text { - } 4 \text { times/wk, } 60 \% \mathrm{VO}_{2} \\
\max , 12 \mathrm{kcal} / \mathrm{kg} / \mathrm{wk}\end{array}$ & $\begin{array}{l}\text { No changes in C-reactive } \\
\text { protein, IL-6, and TNF- } \alpha\end{array}$ \\
\hline Ross et al., 2000 [32] & Aerobic & Obese men & $\begin{array}{l}\text { 3-month, energy expenditure per } \\
\text { exercise session } 700 \mathrm{kcal}\end{array}$ & $\begin{array}{l}\uparrow \text { insulin sensitivity/weight } \\
\text { loss }\end{array}$ \\
\hline Nassis et al., 2005 [70] & Aerobic & $\begin{array}{l}\text { Overweight and } \\
\text { obese adolescent } \\
\text { girls }\end{array}$ & $\begin{array}{l}12 \mathrm{wk}, 3 \text { times/wk, } 40 \mathrm{~min} / \mathrm{session} \text {, } \\
\text { heart beat more than } 150\end{array}$ & $\uparrow$ insulin sensitivity \\
\hline Stewart et al., 2005 [72] & & $\begin{array}{l}\text { Overweight and } \\
\text { obese adults }\end{array}$ & $\begin{array}{l}\text { 6-month, American College of } \\
\text { Sports Medicine guidelines }\end{array}$ & $\begin{array}{l}\text { No changes in insulin } \\
\text { sensitivity, } \downarrow \text { body fat levels }\end{array}$ \\
\hline Yassine et al., 2009 [73] & Aerobic & $\begin{array}{l}\text { Older overweight } \\
\text { and obese }\end{array}$ & $\begin{array}{l}12 \mathrm{wk}, 50-60 \mathrm{~min} / \text { day, } \sim 70 \% \mathrm{VO}_{2} \\
\max \end{array}$ & $\begin{array}{l}\uparrow \text { insulin sensitivity in } \\
\text { combination with diet }\end{array}$ \\
\hline Solomon et al., 2009 [76] & Aerobic & $\begin{array}{l}\text { Older overweight } \\
\text { and obese }\end{array}$ & $\begin{array}{l}\text { 7-day, } 80-85 \% \mathrm{VO}_{2} \max \\
60 \mathrm{~min} / \text { session }\end{array}$ & $\begin{array}{l}\uparrow \text { insulin sensitivity, TG, } \\
\text { total cholesterol }\end{array}$ \\
\hline Durstine et al., 2001 [77] & Aerobic & Various & $\begin{array}{l}\text { A quantitative study, } 24-32 \mathrm{~km} / \mathrm{wk} \\
\text { of brisk walking }\end{array}$ & $\uparrow \mathrm{HDL}, \downarrow \mathrm{TG}$ \\
\hline Fenkci et al., 2006 [78] & $\begin{array}{l}\text { Aerobic and } \\
\text { resistance }\end{array}$ & Obese women & $20 \mathrm{wk}, 32 \mathrm{~km} / \mathrm{wk}, 65-80 \% \mathrm{VO}_{2} \max$ & $\downarrow$ total cholesterol, $\downarrow$ TG \\
\hline Shah et al., 2009 [79] & $\begin{array}{l}\text { Aerobic and } \\
\text { resistance }\end{array}$ & $\begin{array}{l}\text { Obese older } \\
\text { adults }\end{array}$ & $\begin{array}{l}\text { 6-month, } 4 \text { days/wk, } 30 \text { min aerobic } \\
+30 \text { resistance }+15 \mathrm{~min} \text { balance } \\
\text { exercises/day, } 70 \% \mathrm{VO}_{2} \max \\
\text { Initial face }=[65 \% 1-\mathrm{RM}, 8-10 \\
\text { repetitions }] \\
\text { Normal face }=[80 \% 1-\mathrm{RM}, 6-8 \\
\text { repetitions }]\end{array}$ & $\downarrow \mathrm{TG}, \uparrow \mathrm{HDL}$ \\
\hline
\end{tabular}

$\mathrm{VO}_{2}$ max: maximal oxygen uptake, kg: kilograms, kcal: kilocalories, IL-6: interleukin-6, IL-18: interleukin-18, IL-10: interleukin-10, TNF- $\alpha$ : tumour necrosis factor- $\alpha$, TG: triglycerides, HDL: high density lipoprotein.

the metabolic syndrome [75]. Evidence showed that shortterm aerobic exercise ( 7 days at $80-85 \%$ of $\mathrm{VO}_{2}$ max for $60 \mathrm{~min} / \mathrm{session}$ ) in older obese individuals improved metabolic indices (i.e., fasting glucose, insulin levels, triglycerides, and cholesterol) [76]. Similarly, Durstine and colleagues [77] implemented a $24-32 \mathrm{~km} /$ week walking exercise that increased high density lipoprotein by $4-37 \%$. In the same study, a 4-22\% reduction of circulating triglycerides was also recorded without a change in low density lipoprotein levels [77].

The frequency and duration of exercise play an important role in determining lipid profile improvements in overweight and obese individuals as indicated from Kraus and colleagues [80]. In the aforementioned study, 111 overweight and obese middle-aged adults were placed into one of four groups for eight months (three exercise groups and a control group). The three exercise groups included a high-amount-high-intensity aerobic exercise group (jogging $32 \mathrm{~km} /$ week at $65-80 \% \mathrm{VO}_{2}$ $\max$ ), a low-amount-high-intensity aerobic exercise group (jogging $19.2 \mathrm{~km} /$ week at $65-80 \% \mathrm{VO}_{2} \max$ ), and a lowamount-moderate-intensity aerobic exercise group (walking $12 \mathrm{~min} /$ week at $40-55 \% \mathrm{VO}_{2} \max$ ). The results showed an improved lipid profile in the high-amount-high-intensity aerobic exercise group that was suggested to occur due to the amount of exercise rather than the intensity of exercise [80]. In another study, metabolic parameters were examined in 60 obese women after a 20 -week resistance or aerobic exercise intervention. The results showed a significant reduction in triglycerides and total cholesterol for both groups (i.e., resistance and aerobic exercise) [78].

Improvements in plasma triglycerides, high density lipoprotein concentration, and diastolic blood pressure were assessed in obese older adults after a combined 6-month 
dietary and exercise intervention [79]. In this study the 90minute exercise program included a combination of aerobic and resistance training as well as extensive flexibility and balance exercises [79]. Indeed, it has been suggested that exercise is more effective than diet in raising high density lipoprotein levels in obese individuals $[81,82]$. It is not completely clear if this improvement comes from exercise or from participants' changes in body composition. In general, based on the available evidence exercise training may improve the lipid profile of obese and overweight individuals. The effects of exercise on the lipid profile of overweight and obese individuals are summarized in Table 2.

\section{Exercise for Pregnant Overweight and Obese Women}

Overweight and obesity during pregnancy are a serious issue and need to be considered. Some suggestions from recent studies include proper types of exercise for overweight and obese pregnant women, yet this topic needs further exploration and more reliable evidence that will enable experts to easily plan exercise interventions. Nevertheless, Mottola [83] has proposed exercise interventions for overweight and obese pregnant women to control their weight. It is suggested that 34 aerobic exercise sessions per week, in the heart rate zone of $110-131 \mathrm{bpm}$ for the ages of 20-29 years and 108-127 bpm for the ages of 30-39 years, might be suitable for these women. In addition, it was also recommended by the same study that a pregnant woman should start with 15 minutes of aerobic exercise per week and aim for at least 150 minutes per week [83].

\section{Psychological Factors Related to Exercise in Overweight and Obese Individuals}

Overweight and obese individuals experience obstacles that may deter them from exercise participation such as low selfefficacy, difficulties associated with learning a new physical activity, access to proper facilities for exercise, a high cost of programs, and different cultures [84]. Self-determination theory supports that self-determined behavior in combination with a social support network leads to improved psychological well-being [85]. In this light, overweight and obese individuals can be motivated to carry out their obesity treatment [86]. According to Vieira and colleagues [86] women with high scores in health-related quality of life were those who were physically active and enjoying exercise.

Exercise may reduce negative mood state and anxiety levels as well as depression due to, at least in part, the secretion of endorphins [87]. Furthermore, exercise significantly decreases the risk of depression symptoms in a general obese population [87, 88]. Additionally, chronic stress plays an essential role in the development of obesity. Stress causes the secretion of glucocorticoids that increases appetite leading to increased food consumption and insulin secretion $[89,90]$. Thus, obesity treatment should include stress management in combination with weight loss. An exercise-induced reduction in stress can lower fat deposition, increase energy expenditure, lower energy intake, and promote weight loss [91].

Another concern for overweight and obese individuals is body profile that affects the motivation of those individuals to do exercise. It was found that higher BMI scores are associated with negative health outcomes in obese patients with type 2 diabetes and individuals at high risk for diabetes [92]. Nevertheless, the obese individuals with type 2 diabetes were least expected to lose weight and/or participate in an exercise training program. The investigators suggested that BMI, not the risk of type 2 diabetes, is the probable reason for the above view [92]. Alternatively, depression that may be experienced in overweight and obese individuals could contribute to the development of type 2 diabetes. Specifically, it was revealed by a meta-analysis that $25 \%$ of type 2 diabetic cases could be attributed, at least in part, to depression [93]. Furthermore, in individuals that are suffering from depression, inactivity was a strong risk factor for type 2 diabetes, even if the individuals were not overweight or obese [93]. Indeed, exercise and physical activity have been shown to reduce not only anxiety and depression symptoms but also the risk of death from obesity [87]. Interestingly, aerobic exercise interventions can be more effective in depression treatment than antidepressant medication (sertraline) and placebo interventions [87]. It is crucial to provide psychological support for obese and overweight individuals in combination with weight management interventions to overcome obstacles such as low self-efficacy, anxiety, and depression.

\section{Discussion}

The aim of this review was to summarize the current research to elucidate the impact of exercise training on biological and psychological health indices in overweight and obese individuals. According to the current evidence we suggest that exercise is a suitable method for promoting overall physical and psychological health particularly because exercise-induced adaptations occur across a multitude of systems within the active human. In addition, it is necessary to take into consideration the kinematic difficulties that some overweight and obese individuals experience. For example, cycling may be a more appropriate exercise intervention at first, compared with walking or jogging [94]. Moreover, experts need to consider the type and intensity of exercise as well as the levels of psychological well-being that may influence participation and the expected results. It is proposed that designing fun and attractive activities or exercise interventions could help the above purpose [95].

The current research evidence suggests that aerobic or a combination of aerobic and resistance exercise has positive impact on weight management even without following a dietary program, because of the positive exercise-induced biological changes. In general, aerobic exercise may decrease circulating leptin that may contribute, at least in part, to a reduction of adipose tissue accumulation [41], particularly when accompanied by weight loss [43]. Additionally, chronic exercise may increase circulating adiponectin [35] that may reduce circulating levels of free fatty acids [48] and glucose production from the liver $[48,49]$. Aerobic exercise may also 
increase growth hormone secretion that has been shown to be related to the reduction of abdominal fat in obese adults [31]. Similarly, long-term aerobic exercise increased circulating ghrelin levels in overweight individuals that were negatively associated with inflammatory biomarkers [58].

Aerobic exercise may induce potent anti-inflammatory properties in overweight and obese individuals [63] and may improve insulin sensitivity in overweight and obese individuals, particularly when accompanied by weight loss [74]. Furthermore, aerobic exercise training at a moderate intensity improved the lipid profile in overweight and obese individuals independent of weight loss [75]. Specifically, aerobic and resistance exercise have been shown to reduce triglycerides and total cholesterol in obese populations [78] and may be more effective than diet in raising high density lipoprotein levels [81, 82]. Finally, aerobic exercise interventions may improve psychological factors such as anxiety, body image, and depression in obese individuals [87].

Future research should examine the influence of exercise on changes in negative attitudes of overweight and obese individuals. Additionally, there is a dearth of published data examining obese children less than 12 years of age in relation to all the above biological and psychological measures. We, therefore, advocate that future research should focus on the above factors related to obesity in children, in order to prevent obesity during adulthood. In conclusion, exercise for overweight and obese individuals is essential due to its beneficial effects on important biological indices as well as on an individual's psychological status through an improvement in mental health.

\section{Conflict of Interests}

The authors declare that there is no conflict of interests regarding the publication of this paper.

\section{References}

[1] WHO, "Overweight and obesity (high body mass index)," in Comparative Quantification of Health Risks, A. D. L. M. Ezzati, A. Rodgers, and C. J. L. Murray, Eds., chapter 8, WHO, Geneva, Switzerland, 2004.

[2] WHO, "Obesity and overweight," 2010, http://www.who.int/ mediacentre/factsheets/fs311/en/.

[3] D. M. Okay, P. V. Jackson, M. Marcinkiewicz, and M. N. Papino, "Exercise and Obesity," Primary Care-Clinics in Office Practice, vol. 36, no. 2, pp. 379-393, 2009.

[4] WHO, "Review of best practice in interventions to promote physical activity in developing countries," in WHO Workshop on Physical Activity and Public Health, S. S. A. Bauman, M. Lewicka, T. Armstrong, V. Candeias, and J. Richards, Eds., WHO, Beijing, China, 2005.

[5] A. E. Carrillo and A. D. Flouris, "Emerging trends in estimating energy expenditure," Journal of Applied Physiology, vol. 111, no. 2, p. 612, 2011.

[6] J. A. Berlin and G. A. Colditz, "A meta-analysis of physical activity in the prevention of coronary heart disease," The American Journal of Epidemiology, vol. 132, no. 4, pp. 612-628, 1990.
[7] K. E. Powell, P. D. Thompson, C. J. Caspersen, and J. S. Kendrick, "Physical activity and the incidence of coronary heart disease," Annual Review of Public Health, vol. 8, pp. 253-287, 1987.

[8] K. M. Ross, V. A. Milsom, K. A. Rickel et al., "The contributions of weight loss and increased physical fitness to improvements in health-related quality of life," Eating Behaviors, vol. 10, no. 2, pp. 84-88, 2009.

[9] WHO, "Physical activity," 2012, http://www.who.int/topics/ physical_activity/en/.

[10] A. S. Greenberg and M. S. Obin, "Obesity and the role of adipose tissue in inflammation and metabolism," The American Journal of Clinical Nutrition, vol. 83, no. 2, pp. 461S-465S, 2006.

[11] D. T. Fahey, M. P. Insel, and T. W. Roth, Fit \& Well: Core Concepts and Labs in Physical Fitness and Wellness, McGraw-Hill, New York, NY, USA, 2010.

[12] L. de Koning, A. T. Merchant, J. Pogue, and S. S. Anand, "Waist circumference and waist-to-hip ratio as predictors of cardiovascular events: meta-regression analysis of prospective studies," European Heart Journal, vol. 28, no. 7, pp. 850-856, 2007.

[13] F. Tesfaye, P. Byass, and S. Wall, "Populationbased prevalence of high blood pressure among adults in Addis Ababa: uncovering a silent epidemic," BMC Cardiovascular Disorders, vol. 9, article 39, 2009.

[14] T. E. Hyde and M. S. Gengenbach, Eds., Conservative Management of Sports Injuries, Jones \& Bartlett, Sudbury, Mass, USA, 2nd edition, 2007.

[15] A. E. Carrillo and A. D. Flouris, "Caloric restriction and longevity: effects of reduced body temperature," Ageing Research Reviews, vol. 10, no. 1, pp. 153-162, 2011.

[16] C. Howe, R. Harris, and B. Gutin, "A 10-month physical activity intervention improves body composition in young black boys," Journal of Obesity, vol. 2011, Article ID 358581, 8 pages, 2011.

[17] A. W. Ha, J. H. Kim, D. J. Shin et al., "Eating habits, obesity related behaviors, and effects of Danhak exercise in elderly Koreans," Nutrition Research and Practice, vol. 4, no. 4, pp. 295302, 2010.

[18] J. N. Davis, A. Tung, S. S. Chak et al., "Aerobic and strength training reduces adiposity in overweight latina adolescents," Medicine and Science in Sports and Exercise, vol. 41, no. 7, pp. 1494-1503, 2009.

[19] S. Lee, J. L. Kuk, L. E. Davidson et al., "Exercise without weight loss is an effective strategy for obesity reduction in obese individuals with and without type 2 diabetes," Journal of Applied Physiology, vol. 99, no. 3, pp. 1220-1225, 2005.

[20] M. J. Dekker, T. E. Graham, T. C. Ooi, and L. E. Robinson, "Exercise prior to fat ingestion lowers fasting and postprandial VLDL and decreases adipose tissue IL-6 and GIP receptor mRNA in hypertriacylglycerolemic men," Journal of Nutritional Biochemistry, vol. 21, no. 10, pp. 983-990, 2010.

[21] M. J. Dekker, S. Lee, R. Hudson et al., "An exercise intervention without weight loss decreases circulating interleukin-6 in lean and obese men with and without type 2 diabetes mellitus," Metabolism, vol. 56, no. 3, pp. 332-338, 2007.

[22] S. B. Votruba, M. A. Horvitz, and D. A. Schoeller, "The role of exercise in the treatment of obesity," Nutrition, vol. 16, no. 3, pp. 179-188, 2000.

[23] S. N. Blair, "Evidence for success of exercise in weight loss and control," Annals of Internal Medicine, vol. 119, no. 7, pp. 702-706, 1993. 
[24] R. Wing, "Behavioral weight control," in Handbook of Obesity, T. Wadden and A. Stunkard, Eds., The Guilford Press, New York, NY, USA, 2002.

[25] M. Perri and J. Corsica, "Improving the maintenance of weight lost in behavioral treatment of obesity," in Handbook of Obesity, T. Wadden and A. Stunkard, Eds., pp. 357-394, The Guilford Press, New York, NY, USA, 2002.

[26] A. Lang and E. S. Froelicher, "Management of overweight and obesity in adults: behavioral intervention for long-term weight loss and maintenance," European Journal of Cardiovascular Nursing, vol. 5, no. 2, pp. 102-114, 2006.

[27] M. E. Riou, E. Doucet, V. Provencher et al., "Influence of physical activity participation on the associations between eating behaviour traits and body mass index in healthy postmenopausal women," Journal of Obesity, vol. 2011, Article ID 465710, 9 pages, 2011.

[28] M. Halle, A. Berg, U. Garwers, D. Grathwohl, W. Knisel, and J. Keul, "Concurrent reductions of serum leptin and lipids during weight loss in obese men with type II diabetes," The American Journal of Physiology-Endocrinology and Metabolism, vol. 277, no. 2, part 1, pp. E277-E282, 1999.

[29] T. Yamaguchi, A. Saiki, K. Endo, Y. Miyashita, and K. Shirai, "Effect of exercise performed at anaerobic threshold on serum growth hormone and body fat distribution in obese patients with type 2 diabetes," Obesity Research and Clinical Practice, vol. 5, no. 1, pp. e9-e16, 2011.

[30] G. R. Hunter, D. W. Brock, N. M. Byrne, P. C. Chandler-Laney, P. Del Corral, and B. A. Gower, "Exercise training prevents regain of visceral fat for 1 year following weight loss," Obesity, vol. 18, no. 4, pp. 690-695, 2010.

[31] B. A. Irving, J. Y. Weltman, J. T. Patrie et al., "Effects of exercise training intensity on nocturnal growth hormone secretion in obese adults with the metabolic syndrome," Journal of Clinical Endocrinology and Metabolism, vol. 94, no. 6, pp. 1979-1986, 2009.

[32] R. Ross, D. Dagnone, P. J. H. Jones et al., "Reduction in obesity and related comorbid conditions after diet-induced weight loss or exercise-induced weight loss in men: a randomized, controlled trial," Annals of Internal Medicine, vol. 133, no. 2, pp. 92103,2000 .

[33] H. J. Leidy, J. K. Gardner, B. R. Frye et al., "Circulating ghrelin is sensitive to changes in body weight during a diet and exercise program in normal-weight young women," Journal of Clinical Endocrinology and Metabolism, vol. 89, no. 6, pp. 2659-2664, 2004.

[34] L. M. Redman, J. D. Veldhuis, J. Rood, S. R. Smith, D. Williamson, and E. Ravussin, "The effect of caloric restriction interventions on growth hormone secretion in nonobese men and women," Aging Cell, vol. 9, no. 1, pp. 32-39, 2010.

[35] T. Kondo, I. Kobayashi, and M. Murakami, "Effect of exercise on circulating adipokine levels in obese young women," Endocrine Journal, vol. 53, no. 2, pp. 189-195, 2006.

[36] H. I. Katcher, A. M. Hill, J. L. G. Lanford, J. S. Yoo, and P. M. KrisEtherton, "Lifestyle approaches and dietary strategies to lower LDL-cholesterol and triglycerides and raise HDL-cholesterol," Endocrinology and Metabolism Clinics of North America, vol. 38, no. 1, pp. 45-78, 2009.

[37] L. V. Sjostrom, "Mortality of severely obese subjects," The American Journal of Clinical Nutrition, vol. 55, no. 2, supplement, pp. 516S-523S, 1992.
[38] M.C. Pouliot, J. Despres, A. Nadeau et al., "Visceral obesity in men: associations with glucose tolerance, plasma insulin, and lipoprotein levels," Diabetes, vol. 41, no. 7, pp. 826-834, 1992.

[39] R. R. Kraemer, G. R. Kraemer, E. O. Acevedo et al., "Effects of aerobic exercise an serum leptin levels in obese women," European Journal of Applied Physiology and Occupational Physiology, vol. 80, no. 2, pp. 154-158, 1999.

[40] K. Sato, T. Kawamura, and S. Yamagiwa, "The "Senobi" breathing exercise is recommended as first line treatment for obesity," Biomedical Research, vol. 31, no. 4, pp. 259-262, 2010.

[41] R. R. Kraemer and D. Castracane, "Effect of acute and chronic exercise on ghrelin and adipocytokines during pubertal development," Medicine and Sport Science, vol. 55, pp. 156-173, 2010.

[42] N. Gallardo, E. Bonzón-Kulichenko, T. Fernández-Agulló et al., "Tissue-specific effects of central leptin on the expression of genes involved in lipid metabolism in liver and white adipose tissue," Endocrinology, vol. 148, no. 12, pp. 5604-5610, 2007.

[43] L. Ozcan, A. S. Ergin, A. Lu et al., "Endoplasmic reticulum stress plays a central role in development of leptin resistance," Cell Metabolism, vol. 9, no. 1, pp. 35-51, 2009.

[44] A. Weltman, C. J. Pritzlaff, L. Wideman et al., "Intensity of acute exercise does not affect serum leptin concentrations in young men," Medicine and Science in Sports and Exercise, vol. 32, no. 9, pp. 1556-1561, 2000.

[45] R. R. Kraemer, R. J. Durand, E. O. Acevedo et al., "Effects of high-intensity exercise on leptin and testosterone concentrations in well-trained males," Endocrine, vol. 21, no. 3, pp. 261265, 2003.

[46] W. M. Kohrt, M. Landt, and S. J. Birge Jr., "Serum leptin levels are reduced in response to exercise training, but not hormone replacement therapy, in older women," Journal of Clinical Endocrinology and Metabolism, vol. 81, no. 11, pp. 3980-3985, 1996.

[47] L. Perusse, G. Collier, J. Gagnon et al., "Acute and chronic effects of exercise on leptin levels in humans," Journal of Applied Physiology, vol. 83, no. 1, pp. 5-10, 1997.

[48] A. S. Lihn, S. B. Pedersen, and B. Richelsen, "Adiponectin: action, regulation and association to insulin sensitivity," Obesity Reviews, vol. 6, no. 1, pp. 13-21, 2005.

[49] A. Camera, E. Hopps, and G. Caimi, "Metabolic syndrome: from insulin resistance to adipose tissue dysfunction," Minerva Medica, vol. 99, no. 3, pp. 307-321, 2008.

[50] B. Yang, L. Chen, Y. Qian et al., "Changes of skeletal muscle adiponectin content in diet-induced insulin resistant rats," Biochemical and Biophysical Research Communications, vol. 341, no. 1, pp. 209-217, 2006.

[51] C. Punyadeera, A. H. G. Zorenc, R. Koopman et al., "The effects of exercise and adipose tissue lipolysis on plasma adiponectin concentration and adiponectin receptor expression in human skeletal muscle," European Journal of Endocrinology, vol. 152, no. 3, pp. 427-436, 2005.

[52] M. A. Ferguson, L. J. White, S. McCoy, H. Kim, T. Petty, and J. Wilsey, "Plasma adiponectin response to acute exercise in healthy subjects," European Journal of Applied Physiology, vol. 91, no. 2-3, pp. 324-329, 2004.

[53] N. Vahl, J. O. L. Jørgensen, C. Skjærbæk, J. D. Veldhuis, H. Ørskov, and J. S. Christiansen, "Abdominal adiposity rather than age and sex predicts mass and regularity of GH secretion in healthy adults," The American Journal of PhysiologyEndocrinology and Metabolism, vol. 272, no. 6, part 1, pp. E1108E1116, 1997. 
[54] N. Filigheddu, V. F. Gnocchi, M. Coscia et al., "Ghrelin and des-acyl ghrelin promote differentiation and fusion of $\mathrm{C} 2 \mathrm{C} 12$ skeletal muscle cells," Molecular Biology of the Cell, vol. 18, no. 3, pp. 986-994, 2007.

[55] V. D. Dixit, E. M. Schaffer, R. S. Pyle et al., "Ghrelin inhibits leptin- and activation-induced proinflammatory cytokine expression by human monocytes and T cells," Journal of Clinical Investigation, vol. 114, no. 1, pp. 57-66, 2004.

[56] M. D. DeBoer, X. Zhu, P. R. Levasseur et al., "Ghrelin treatment of chronic kidney disease: improvements in lean body mass and cytokine profile," Endocrinology, vol. 149, no. 2, pp. 827-835, 2008.

[57] P. S. Morpurgo, M. Resnik, F. Agosti, V. Cappiello, A. Sartorio, and A. Spada, "Ghrelin secretion in severely obese subjects before and after a 3-week integrated body mass reduction program," Journal of Endocrinological Investigation, vol. 26, no. 8, pp. 723-727, 2003.

[58] A. E. Carrillo, M. G. Flynn, K. L. Timmerman, P. M. Coen, M. M. Markofski, and B. D. Pence, "Changes in plasma ghrelin are associated with human monocyte phenotype following exercise training," Medicine and Science in Sports and Exercise, vol. 40, no. 5, p. S433, 2008.

[59] P. Trayhurn and J. H. Beattie, "Physiological role of adipose tissue: white adipose tissue as an endocrine and secretory organ," Proceedings of the Nutrition Society, vol. 60, no. 3, pp. 329-339, 2001.

[60] B. Strasser and W. Schobersberger, "Evidence for resistance training as a treatment therapy in obesity," Journal of Obesity, vol. 2011, Article ID 482564, 9 pages, 2011.

[61] M. Guerre-Millo, "Adiponectin: an update," Diabetes and Metabolism, vol. 34, no. 1, pp. 12-18, 2008.

[62] R. P. Sloan, P. A. Shapiro, R. E. Demeersman et al., "Aerobic exercise attenuates inducible TNF production in humans," Journal of Applied Physiology, vol. 103, no. 3, pp. 1007-1011, 2007.

[63] M. G. Flynn, M. M. Markofski, A. E. Carrillo, C. Armstrong, V. W. Campbell, and D. A. Sedlock, "Exercise training with and without body fat reduction: influence on biomarkers of inflammation," Medicine and Science in Sports and Exercise, vol. 42, no. 10, pp. 65-66, 2010.

[64] K. C. Shih, A. J. Janckila, C. Kwok, L. Ho, Y. Chou, and T. Chao, "Effects of exercise on insulin sensitivity, inflammatory cytokines, and serum tartrate-resistant acid phosphatase $5 \mathrm{a}$ in obese Chinese male adolescents," Metabolism, vol. 59, no. 1, pp. 144-151, 2010.

[65] N. P. E. Kadoglou, F. Iliadis, N. Angelopoulou et al., "The antiinflammatory effects of exercise training in patients with type 2 diabetes mellitus," European Journal of Cardiovascular Prevention and Rehabilitation, vol. 14, no. 6, pp. 837-843, 2007.

[66] B. J. Arsenault, M. Côté, A. Cartier et al., "Effect of exercise training on cardiometabolic risk markers among sedentary, but metabolically healthy overweight or obese post-menopausal women with elevated blood pressure," Atherosclerosis, vol. 207, no. 2, pp. 530-533, 2009.

[67] C. A. Slentz, B. D. Duscha, J. L. Johnson et al., "Effects of the amount of exercise on body weight, body composition, and measures of central obesity: STRRIDE-a randomized controlled study," Archives of Internal Medicine, vol. 164, no. 1, pp. 31-39, 2004.

[68] B. Larsson, P. Björntorp, and G. Tibblin, "The health consequences of moderate obesity," International Journal of Obesity, vol. 5, no. 2, pp. 97-116, 1981.
[69] C. Bogardus, E. Ravussin, and D. C. Robbins, "Effects of physical training and diet therapy on carbohydrate metabolism in patients with glucose intolerance and non-insulin-dependent diabetes mellitus," Diabetes, vol. 33, no. 4, pp. 311-318, 1984.

[70] G. P. Nassis, K. Papantakou, K. Skenderi et al., "Aerobic exercise training improves insulin sensitivity without changes in body weight, body fat, adiponectin, and inflammatory markers in overweight and obese girls," Metabolism, vol. 54, no. 11, pp. 14721479, 2005.

[71] R. S. Weinstock, H. Dai, and T. A. Wadden, "Diet and exercise in the treatment of obesity: effects of 3 interventions on insulin resistance," Archives of Internal Medicine, vol. 158, no. 22, pp. 2477-2483, 1998.

[72] K. J. Stewart, A. C. Bacher, K. Turner et al., "Exercise and risk factors associated with metabolic syndrome in older adults," The American Journal of Preventive Medicine, vol. 28, no. 1, pp. 9-18, 2005.

[73] H. N. Yassine, C. M. Marchetti, R. K. Krishnan, T. R. Vrobel, F. Gonzalez, and J. P. Kirwan, "Effects of exercise and caloric restriction on insulin resistance and cardiometabolic risk factors in older obese adults-a randomized clinical trial," Journals of Gerontology A, vol. 64, no. 1, pp. 90-95, 2009.

[74] K. R. Kelly, L. M. Brooks, T. P. J. Solomon, S. R. Kashyap, V. B. O'Leary, and J. P. Kirwan, "The glucose-dependent insulinotropic polypeptide and glucose-stimulated insulin response to exercise training and diet in obesity," The American Journal of Physiology-Endocrinology and Metabolism, vol. 296, no. 6, pp. E1269-E1274, 2009.

[75] S. Carroll and M. Dudfield, "What is the relationship between exercise and metabolic abnormalities? A review of the metabolic syndrome," Sports Medicine, vol. 34, no. 6, pp. 371-418, 2004.

[76] T. P. J. Solomon, J. M. Haus, K. R. Kelly et al., "Randomized trial on the effects of a 7-d low-glycemic diet and exercise intervention on insulin resistance in older obese humans," The American Journal of Clinical Nutrition, vol. 90, no. 5, pp. 12221229, 2009.

[77] J. L. Durstine, P. W. Grandjean, P. G. Davis, M. A. Ferguson, N. L. Alderson, and K. D. DuBose, "Blood lipid and lipoprotein adaptations to exercise: a quantitative analysis," Sports Medicine, vol. 31, no. 15, pp. 1033-1062, 2001.

[78] S. Fenkci, A. Sarsan, S. Rota, and F. Ardic, "Effects of resistance or aerobic exercises on metabolic parameters in obese women who are not on a diet," Advances in Therapy, vol. 23, no. 3, pp. 404-413, 2006.

[79] K. Shah, A. Stufflebam, T. N. Hilton, D. R. Sinacore, S. Klein, and D. T. Villareal, "Diet and exercise interventions reduce intrahepatic fat content and improve insulin sensitivity in obese older adults," Obesity, vol. 17, no. 12, pp. 2162-2168, 2009.

[80] W. E. Kraus, J. A. Houmard, B. D. Duscha et al., "Effects of the amount and intensity of exercise on plasma lipoproteins," The New England Journal of Medicine, vol. 347, no. 19, pp. 1483-1492, 2002.

[81] S. Rashid and J. Genest, "Effect of obesity on high-density lipoprotein metabolism," Obesity, vol. 15, no. 12, pp. 2875-2888, 2007.

[82] R. S. Schwartz, "The independent effects of dietary weight loss and aerobic training on high density lipoproteins and apolipoprotein A-I concentrations in obese men," Metabolism, vol. 36, no. 2, pp. 165-171, 1987. 
[83] M. F. Mottola, "Exercise prescription for overweight and obese women: pregnancy and postpartum," Obstetrics and Gynecology Clinics of North America, vol. 36, no. 2, pp. 301-316, 2009.

[84] R. Grave, S. Calugi, E. Centis, M. El Ghoch, and G. Marchesini, "Cognitive-behavioral strategies to increase the adherence to exercise in the management of obesity," Journal of Obesity, vol. 2011, Article ID 348293, 11 pages, 2011.

[85] E. L. Deci and R. M. Ryan, "The "what" and "why" of goal pursuits: human needs and the self-determination of behavior," Psychological Inquiry, vol. 11, no. 4, pp. 227-268, 2000.

[86] P. Vieira, J. Mata, M. N. Silva et al., "Predictors of psychological well-being during behavioral obesity treatment in women," Journal of Obesity, vol. 2011, Article ID 936153, 8 pages, 2011.

[87] P. C. Dinas, Y. Koutedakis, and A. D. Flouris, "Effects of exercise and physical activity on depression," Irish Journal of Medical Science, vol. 180, no. 2, pp. 319-325, 2011.

[88] R. Fuchs, "Physical activity and health," in International Encyclopaedia of the Social and Behavioural Sciences, N. Smelser and P. Baltes, Eds., Elsevier, New York, NY, USA, 2001.

[89] V. Drapeau, F. Therrien, D. Richard, and A. Tremblay, "Is visceral obesity a physiological adaptation to stress?" Panminerva Medica, vol. 45, no. 3, pp. 189-195, 2003.

[90] M. F. Dallman, "Stress-induced obesity and the emotional nervous system," Trends in Endocrinology and Metabolism, vol. 21, no. 3, pp. 159-165, 2010.

[91] J. P. Chaput, L. Klingenberg, M. Rosenkilde, J.-A. Gilbert, A. Tremblay, and A. Sjödin, "Physical activity plays an important role in body weight regulation," Journal of Obesity, vol. 2011, Article ID 360257, 11 pages, 2011.

[92] J. R. Gavin III, H. W. Rodbard, K. M. Fox, and S. Grandy, "Association of overweight and obesity with health status, weight management, and exercise behaviors among individuals with type 2 diabetes mellitus or with cardiometabolic risk factors," Risk Management and Health Care Policy, vol. 2, pp. 1-7, 2009.

[93] J. Knapen, D. Vancampfort, B. Schoubs et al., "Exercise for the treatment of depression," The Open Complementary Medicine Journal, vol. 1, pp. 78-83, 2009.

[94] J. Nantel, M. E. Mathieu, and F. Prince, "Physical activity and obesity: biomechanical and physiological key concepts," Journal of Obesity, vol. 2011, Article ID 650230, 10 pages, 2011.

[95] B. I. Deforche, I. M. de Bourdeaudhuij, and A. P. Tanghe, "Attitude toward physical activity in normal-weight, overweight and obese adolescents," Journal of Adolescent Health, vol. 38, no. 5, pp. 560-568, 2006. 

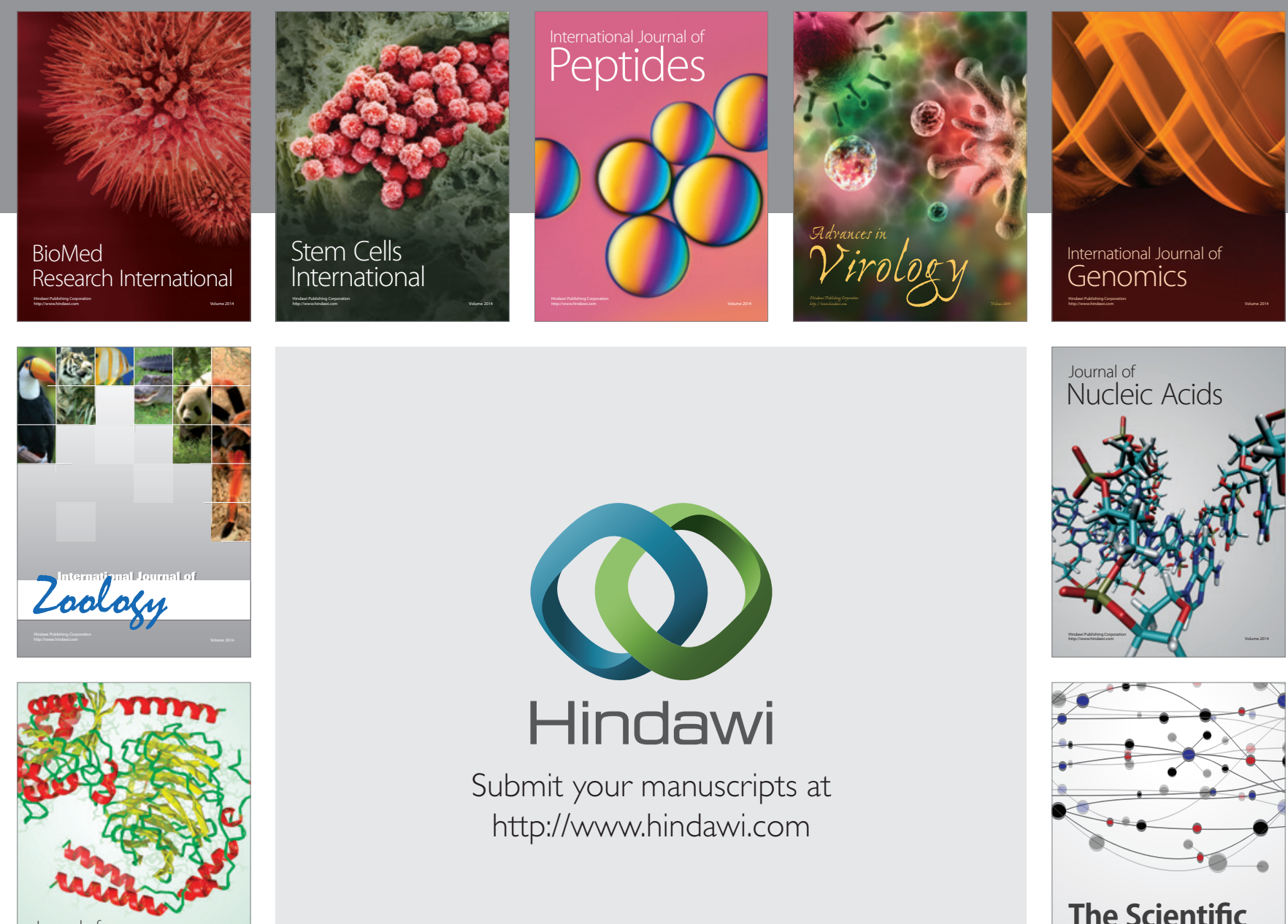

Submit your manuscripts at

http://www.hindawi.com

Journal of
Signal Transduction
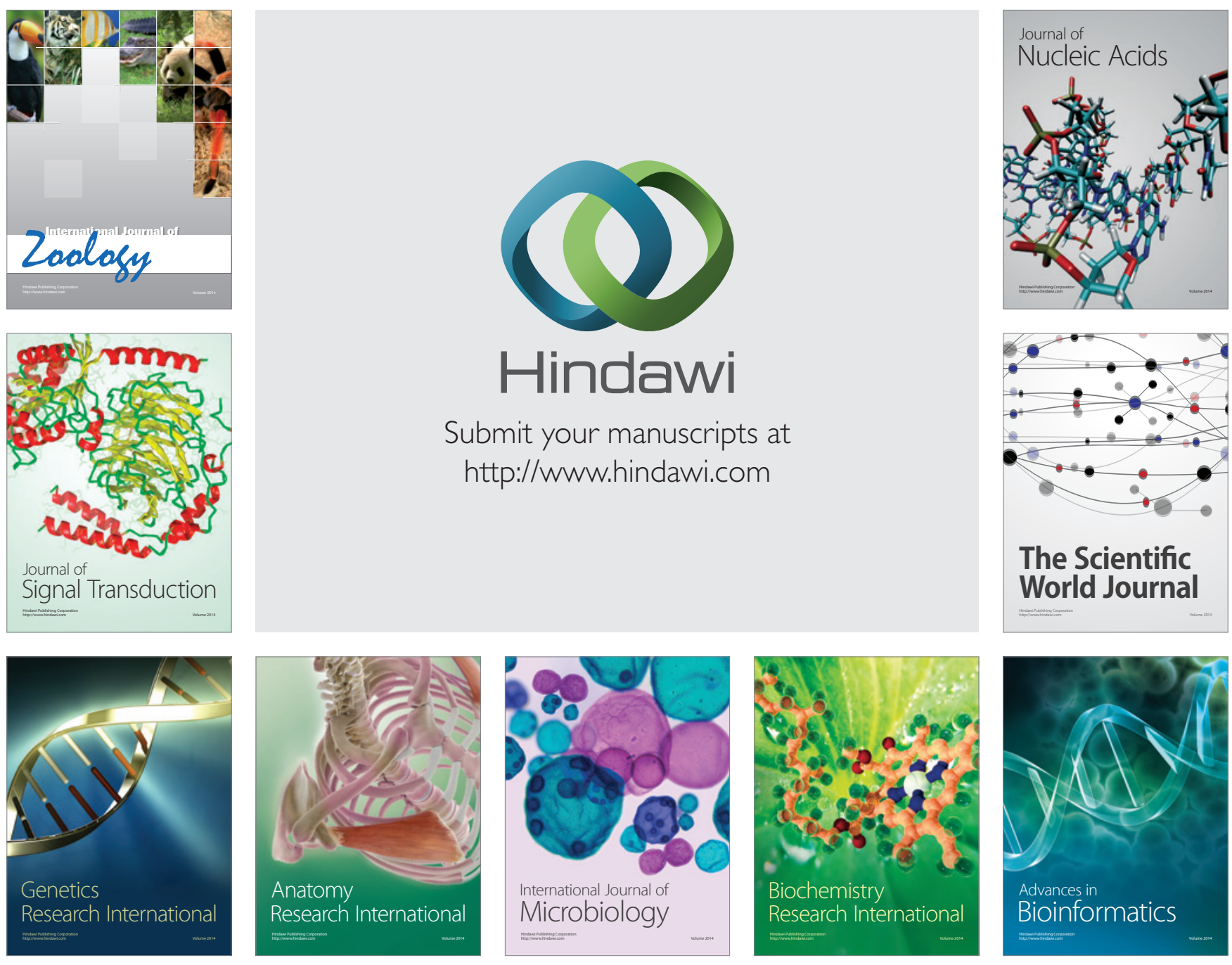

The Scientific World Journal
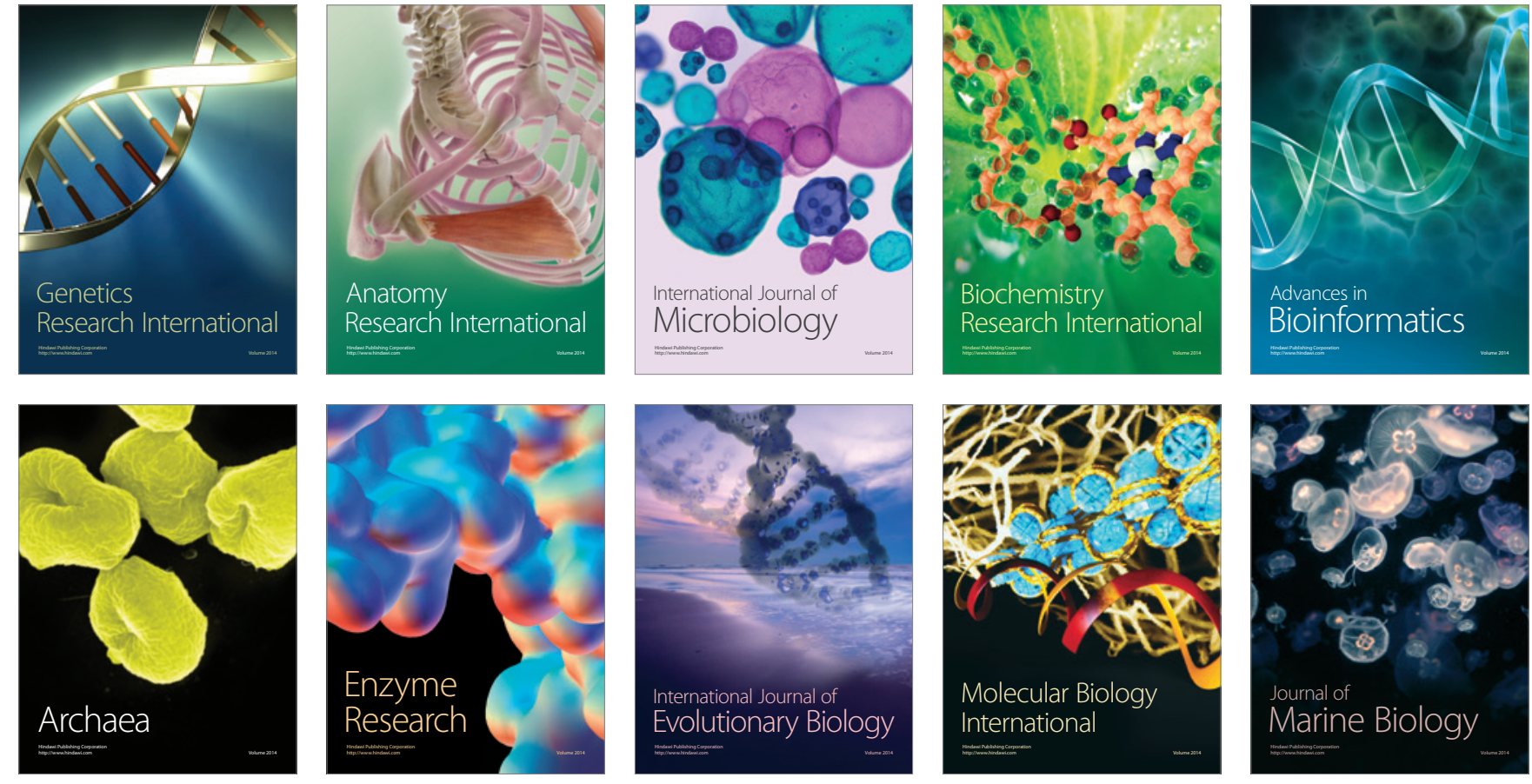